\title{
White Brides, White Mistresses
}

Fog freezing to the greenery, then a skiff of snow-clouds that will crumble later as the snow leopard slips into a boy's dreaming. Neither the boy nor the animal knows of the dream. Their fear of each other doubles their beauty. Their desire stills footfalls and cloaks deep paw prints.

The leopard's eyes do not close when she's caressed. But they do when she's kissed-the kiss is so new.

The boy's arms catch in the snowy pelt with its surprise of warmth deeper in. These are my fingers, the boy says, these are my lips. He senses the small thing he is when he enters her, clinging to her haunches, knowing she feels him barely.

The pressures of her hungers tighten. His whispers, her quiversthese swirl a blizzard about them.

The depths she desires press in on him. The road there is lit like the first dawn, and the distance clear: high jagged peaks! White irises, bridges of ice. 